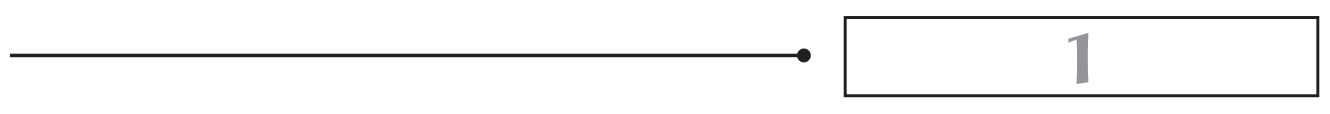

\title{
DO EXERCÍCIO DA SOBERANIA SOBRE OS RECURSOS NATURAIS NO TERRITÓRIO BRASILEIRO
}

\subsection{CONSIDERAÇÕES ACERCA DO PRINCÍPIO DA SOBERANIA SOBRE OS RECURSOS NATURAIS NO DIREITO INTERNACIONAL}

Atualmente é amplamente aceito pelo Direito Internacional o princípio que assegura aos Estados Nacionais a sua soberania permanente sobre os recursos naturais existentes em seu território, conforme estabelecido pela Resolução n. 1.803, adotada pela Assembleia Geral das Nações Unidas em 14 de dezembro de 1962. Tal princípio foi introduzido no ordenamento internacional em um contexto de conflitos entre os países detentores de recursos naturais e as companhias internacionais de exploração e produção desses recursos, notadamente as do setor petrolífero. Segundo reivindicação daqueles, os contratos anteriormente firmados com as empresas petrolíferas concediam a estas vantagens claramente desproporcionais, em detrimento dos interesses dos países hospedeiros, que assistiam ao esgotamento de suas reservas sem receber uma remuneração adequada, motivo por que deveriam ser revistos. As empresas petrolíferas, por sua vez, valiam-se do princípio pacta sunt servanda, segundo o qual os contratos devem ser cumpridos nos termos em que foram acertados.

Em reconhecimento à razoabilidade do pleito das naçōes prejudicadas, foi instituída a Resolução n. 1.803, mencionada anteriormente, bem como outras criadas posteriormente para lidar com a questão, ${ }^{2}$ as quais foram enfáticas em reforçar o

Após, outros instrumentos normativos internacionais se seguiram, reafirmando o direito de soberania dos Estados sobre os recursos naturais existentes em seu território. Segundo Antonio 
princípio da soberania dos Estados sobre os seus recursos naturais. Estabeleceram, ainda, que tais direitos deveriam ser exercidos com vistas a garantir o desenvolvimento nacional e o bem-estar da população do respectivo Estado (art. $1^{\circ}$ da Resolução n. 1.803 da ONU).

Para assegurar o exercício de tais direitos por aquelas nações que já tinham assinado contratos claramente desvantajosos com companhias internacionais e desejavam rever os termos do acordo, no artigo $4^{\circ}$ da Resolução consta a possibilidade de nacionalização, expropriação ou requisição das áreas concedidas, quando existirem razões de utilidade pública, segurança ou interesse nacional que se revelem superiores a meros interesses particulares, seja de agentes internacionais ou nacionais. Em tais casos, deverá ser pago àquele que realizou investimentos uma indenização justa, de acordo com as regras do Estado hospedeiro.

O direito à soberania dos recursos naturais encontra-se garantido também por meio de outro importante instrumento normativo no Direito Internacional, a Convenção de Montego Bay, também conhecida como Lei dos Mares, que regula o exercício da soberania dos Estados sobre os recursos naturais existentes no mar territorial, zona econômica exclusiva e na plataforma continental. ${ }^{3}$

Trindade, "em Resolução adotada em 17 de dezembro de 1973 pela Assembleia Geral da ONU, por 108 votos a favor e um contra e com 16 abstençôes, reafirmou-se o direito inalienável dos Estados à soberania permanente sobre os recursos naturais. (...) Em resolução de 19 de outubro de 1972 sobre o tema, adotada por 39 votos a favor e dois contra, com 23 abstençôes, a UNCTAD reafirmava o direito soberano de todos os países de disporem livremente de seus recursos naturais em prol do seu desenvolvimento nacional” (2003, p. 382-384).

3 Art. 2o Regime jurídico do mar territorial, seu espaço aéreo sobrejacente, leito e subsolo:

1. A soberania do Estado costeiro estende-se além do seu território e das suas águas interiores e, no caso de Estado arquipélago, das suas águas arquipelágicas, a uma zona de mar adjacente designada pelo nome de mar territorial.

2. Esta soberania estende-se ao espaço aéreo sobrejacente ao mar territorial, bem como ao leito e ao subsolo deste mar.

3. A soberania sobre o mar territorial é exercida de conformidade com a presente Convenção e as demais normas de direito internacional.

Art. 56. Direitos, jurisdição e deveres do Estado costeiro na zona econômica exclusiva:

1. Na zona econômica exclusiva, o Estado costeiro tem:

a) direitos de soberania para fins de exploração e aproveitamento, conservação e gestão dos recursos naturais, vivos ou não vivos das águas sobrejacentes ao leito do mar, do leito do mar e seu subsolo, e no que se refere a outras atividades com vista à exploração e aproveitamento da zona para fins econômicos, como a produção de energia a partir da água, das correntes e dos ventos;

b) jurisdição, de conformidade com as disposições pertinentes da presente Convenção, no que se refere a:

I - colocação e utilização de ilhas artificiais, instalações e estruturas; 
No que tange ao conteúdo desse princípio, é importante que se compreenda que a soberania de um país sobre seus recursos naturais não deve ser confundida com o direito de propriedade exercido sobre tais recursos. Este tema será analisado com maiores detalhes no capítulo seguinte. Estes são conceitos distintos, conforme ensinam Omorogbe e Oniemola, ao expor que de acordo com o princípio da soberania, "os Estados têm o direito de determinar o que se entende por propriedade. Em outras palavras, os Estados têm o direito de definir e organizar seus direitos de propriedade" (2010, p. 117, tradução nossa). A partir dessa conclusão, afirmam que um Estado soberano pode atribuir a si mesmo certos direitos, dentre os quais a propriedade do petróleo, por exemplo.

No mesmo sentido, afirma Catherine Redgwell:

o Direito Internacional geralmente não estipula o proprietário ou a forma como deve ser exercido o direito de propriedade que os Estados devem aplicar aos seus recursos energéticos pela sua legislação interna. É de livre escolha do Estado determinar, segundo o seu direito interno, quando os recursos energéticos e a infraestrutura aplicada na sua exploração são propriedade pública ou privada, bem como em que condiçóes, por exemplo, será feita a exploração do petróleo, se com base em arranjos contratuais ou segundo a atribuição de uma licença regulada por normas de direito público, ou qualquer outro instrumento jurídico (2010, p. 100, tradução nossa).

Em suma, o que o Direito Internacional assegura aos Estados Nacionais é o exercício de uma liberdade na escolha da melhor forma para explorar seus recursos. Não impõe a adoção de um regime de propriedade que deve ser seguido, nem algum

II - investigação cientifica marinha;

III - proteção e preservação do meio marinho;

2. No exercício dos seus direitos e no cumprimento dos seus deveres na zona econômica exclusiva nos termos da presente Convenção, o Estado costeiro terá em devida conta os direitos e deveres dos outros Estados e agirá de forma compatível com as disposiçôes da presente Convenção.

Art. 77. Direitos do Estado costeiro sobre a plataforma continental:

1. O Estado costeiro exerce direitos de soberania sobre a plataforma continental para efeitos de exploração e aproveitamento dos seus recursos naturais.

2. Os direitos a que se refere o parágrafo $1^{\circ}$ são exclusivos no sentido de que, se o Estado costeiro não explora a plataforma continental ou não aproveita os recursos naturais da mesma, ninguém pode empreender estas atividades sem o expresso consentimento desse Estado.

3. Os direitos do Estado costeiro sobre a plataforma continental são independentes da sua ocupação, real ou fictícia, ou de qualquer declaração expressa.

4. Os recursos naturais a que se referem as disposiçôes da presente Parte, são os recursos minerais e outros recursos não vivos do leito do mar e subsolo bem como os organismos vivos pertencentes a espécies sedentárias, isto é, aquelas que no período de captura estão imóveis no leito do mar ou no seu subsolo ou só podem mover-se em constante contato físico com esse leito ou subsolo. 
tipo de modelo contratual a ser adotado. Podem optar por qualquer um dos caminhos possíveis, que, conforme exposto por Omorogbe e Oniemola, restringem-se basicamente a dois: 1) pode-se determinar que eles pertencem ao proprietário da terra, conforme ainda se verifica nos Estados Unidos; ou 2) podem pertencer ao Estado, sendo o seu proprietário o ente central ou o ente subnacional onde os recursos estão localizados, tais como províncias, estados ou outro tipo de governo local (2010).

Além disso, quer pertençam a um ente estatal, quer ao particular, ainda existirão diversas nuances que devem ser abordadas pelo ordenamento interno, tendo em vista que o exercício do direito de propriedade envolve, normalmente, uma série de atributos que podem ser desmembrados entre vários sujeitos. Por tais razões, continuam Omorogbe e Oniemola, compreender o que o direito interno define por propriedade e os elementos que envolvem o exercício desse direito torna-se necessário para responder a algumas questões práticas, por exemplo: em que ponto o Estado pode alienar o petróleo ou criar um direito sobre esse bem? Enquanto se encontra ainda no subsolo, concomitantemente à sua extração, ou em momento posterior? (2010, p. 117). A relevância de tais questionamentos será compreendida quando se tratar, no capítulo seguinte, do regime de propriedade aplicável ao petróleo no direito brasileiro e dos limites ao seu exercício.

\subsection{O TERRITÓRIO BRASILEIRO}

O exercício da soberania de um Estado, conforme visto anteriormente, no que tange ao poder de delimitação dos direitos de propriedade sobre seus recursos naturais, se dá sobre aqueles que se encontrem nos estritos limites do seu território nacional. No entanto, a noção exata do que constitui o território nacional não está livre de algumas questões tormentosas, que precisam ser elucidadas para que seja possível compreender até onde vai o direito de soberania do Estado brasileiro sobre os recursos naturais presentes no globo terrestre.

Seguindo as lições de Paulo Borba Casella, define-se a expressão território nacional como:

a base física, ou porção da superfície do globo terrestre, sobre a qual cada estado exerce dominação exclusiva, ou o conjunto de direitos, normalmente enfeixados sob a rubrica da soberania. O Estado se define, fisicamente, pela sua territorialidade. E esta se define pelo espaço, sobre o qual o estado exerce o conjunto de poderes, normalmente enfeixados sob a denominação de soberania (2009, p. 19-20).

Por muito tempo a noção de território de um Estado baseava-se, de acordo com o mesmo autor, apenas em sua dimensão horizontal, segundo as linhas de longitude e latitude. Não havia nenhuma preocupação em regular, por exemplo, a 
exploração do subsolo marinho ou do espaço aéreo correspondente, mesmo porque não existia tecnologia que possibilitasse o seu uso. No entanto, a partir do início do século XX, essa concepção de território começou a se alterar, agregando-se a dimensão vertical, com a regulação do domínio aéreo e do subsolo oceânico (2009).

A atual dimensão do Estado brasileiro, que leva em consideração todas essas dimensões, foi sendo construída ao longo da história, por meio de uma série de tratados. Com relação ao espaço terrestre, encontra-se este definido pela Resolução n. 5 do Instituto Brasileiro de Geografia e Estatística (IBGE), de 10 de outubro de 2002, na qual se atribui uma área superior a oito milhões e quinhentos mil quilômetros quadrados. ${ }^{4}$ Considerando a dimensão vertical nesta porção do território, a soberania brasileira se estende de maneira ilimitada em direção ao subsolo e ao espaço aéreo correspondente.

No que tange ao espaço marítimo, o limite territorial dos Estados costeiros nessa área encontra-se regulado pela Convenção das Nações Unidas sobre o Direito do Mar (denominada Convemar), assinada em 10 de dezembro de 1982, em Montego Bay, na Jamaica, ocasião em que foi definido no Direito Internacional um regime jurídico definitivo acerca do Direito do Mar.

Referida Convenção entrou em vigor, internacionalmente, em 16 de novembro de 1994, doze meses após o depósito do $60^{\circ}$ instrumento de ratificação. No Brasil, ele passou a vigorar por meio do Decreto n. 1.530/95. Conforme ensina Paulo Borba Casella, "a capacidade da Convenção em refletir o conteúdo do costume e adequar-se aos interesses dos diferentes estados ensejou à Convenção do Direito do Mar contar com mais de cento e cinquenta ratificaçôes, mais que o dobro do necessário para sua entrada em vigor" (2009, p. 372).

A partir de então, foram adotados os seguintes critérios para a definição do espaço marítimo no Direito Internacional Público:

- Largura do Mar Territorial de 12 milhas marítimas, contadas a partir da linha de baixa-mar ao longo da costa, tal como indicada nas cartas marítimas de grande escala, reconhecidas oficialmente pelo Estado costeiro, onde este exerce soberania plena (arts. $3^{\circ}$ e $5^{\circ}$ ).

- Zona Contígua de 24 milhas marítimas, contadas a partir das linhas de base que servem para medir a largura do mar territorial, onde o Estado costeiro pode tomar as medidas de fiscalização necessárias a evitar e reprimir as infrações às leis e regulamentos aduaneiros, fiscais, de imigração ou sanitárias no seu território ou no seu mar territorial.

Segundo a Resolução n. 5/2002 do IBGE, o espaço terrestre do Brasil corresponde a uma área total de $8.514 .876,599 \mathrm{~km}^{2}$. 
- Zona Econômica Exclusiva de 200 milhas, contadas das linhas de base, a partir das quais se mede a largura do mar territorial. Na zona econômica exclusiva, o Estado costeiro tem: a) direitos de soberania para fins de exploração e aproveitamento, conservação e gestão dos recursos naturais, vivos ou não vivos, das águas sobrejacentes ao leito do mar, do leito do mar e seu subsolo, e no que se refere a outras atividades com vistas à exploração e aproveitamento da zona para fins econômicos, como a produção de energia a partir da água, das correntes e dos ventos; b) jurisdição, de conformidade com as disposiçôes pertinentes da presente Convenção, no que se refere a: 1) colocação e utilização de ilhas artificiais, instalações e estruturas; 2) investigação cientifica marinha; 3) proteção e preservação do meio marinho.

Além desses, a Convenção delimitou o espaço marítimo ao qual se convencionou chamar de plataforma continental. Dada a maior complexidade do tema e o conjunto de controvérsias envolvendo os seus limites externos, aborda-se a questão com maior detalhamento no tópico seguinte, uma vez que é na plataforma continental que se encontra o petróleo, recurso natural sobre o qual se busca conhecer os limites dos direitos de soberania do Brasil para fins de apropriação e aproveitamento econômico.

\subsection{DO EXERCÍCIO DA SOBERANIA SOBRE OS RECURSOS NATURAIS DA PLATAFORMA CONTINENTAL BRASILEIRA}

Casella elucida o conceito de plataforma continental, explicando que "os continentes não baixam abruptamente até as profundezas oceânicas e, em muitos casos, existe espécie de planície submarina, ao longo de muitas costas, que se inclina, natural e gradativamente, até grande distância do litoral, formando aquilo que se denominou plataforma continental ou plataforma submarina” (2009, p. 421).

De acordo com o parágrafo $1^{\circ}$ do artigo 76 da Convenção de Montego Bay, a plataforma continental de um Estado pode se estender até os seguintes limites: I por toda a extensão do prolongamento natural do seu território terrestre até o bordo exterior da margem continental; ou II - até uma distância de 200 milhas marítimas das linhas de base, a partir das quais se mede a largura do mar territorial, nos casos em que o bordo exterior da margem continental não atinja essa distância.

A margem continental, com base no parágrafo $3^{\circ}$ do artigo em questão, compreende o prolongamento submerso da massa terrestre do Estado costeiro e é constituída pelo leito e subsolo da plataforma continental, pelo talude e pela elevação continental. Não abarca nem os grandes fundos oceânicos, com as suas cristas oceânicas, nem o seu subsolo.

Com base em tais regras tem-se o seguinte: ou o Estado possui uma margem continental extensa, que ultrapassa 200 milhas (situação 1), ou o Estado possui 
uma margem continental estreita, inferior ou igual a 200 milhas (situação 2). Neste último caso, a Lei assegura ao Estado o direito de domínio sobre uma faixa marítima de 200 milhas, contadas a partir da sua costa, sendo este o limite máximo da sua plataforma continental, coincidente, portanto, com o limite da sua zona econômica exclusiva.

Na primeira situação, diante da possibilidade da margem continental de um Estado ser demasiadamente extensa, entendeu-se por bem que fosse arbitrado algum tipo de limite à possibilidade de domínio sobre o espaço marítimo adjacente a sua costa. Segundo Paulo Borba Casella, na elaboração da Convenção sobre o Direito do Mar procurou-se conciliar a manutenção do princípio da liberdade dos mares com a liberdade dos Estados costeiros de explorar os recursos naturais na porção do seu território que se estende mar adentro, tanto os do leito quanto os do seu subsolo (2009).

Desse modo, estabeleceu-se a seguinte regra no parágrafo $5^{\circ}$ do artigo $76 \mathrm{da}$ Convenção, no que concerne aos limites exteriores da plataforma continental desses Estados: I - admite-se a extensão da plataforma continental até uma distância máxima de 350 milhas, contadas da linha de base, a partir da qual se mede o mar territorial. No entanto, se a extensão da margem continental for inferior, por exemplo, a 300 milhas, este será o limite da plataforma continental (critério horizontal); II - alternativamente, permitiu-se a adoção do chamado "critério vertical", com base no qual a plataforma continental de um Estado pode se estender além das referidas 350 milhas, contanto que não exceda 100 milhas marítimas da isóbata ${ }^{5}$ de 2.500 metros, linha esta que une profundidades de 2.500 metros (critério vertical).

A competência para determinar a extensão do domínio marítimo além das 200 milhas marítimas, segundo os mencionados critérios horizontal e vertical, é do próprio Estado interessado, que deverá, de acordo com o parágrafo $4^{\circ}$, alínea $a$, do mesmo artigo 76, "estabelecer o bordo exterior da margem continental, quando essa margem se estender além das 200 milhas marítimas das linhas de base, a partir das quais se mede a largura do mar territorial".

No entanto, o parágrafo $8^{\circ}$ do artigo em comento estabelece a necessidade de o país interessado submeter à Comissão de Limites da Plataforma Continental as informações que contiver sobre os limites da sua plataforma continental, além das 200 milhas marítimas. Após o recebimento desses documentos, o dispositivo determina

Isóbata - s.f. Numa carta barométrica, linha que une os pontos de igual profundidade do fundo dos mares e dos oceanos. Dicionário on-line de português. Disponível em: <http:// www.dicio.com.br/isobata>. Acesso em: 15 dez. 2010. 
que "a Comissão fará recomendaçôes aos Estados costeiros sobre questões relacionadas com o estabelecimento dos limites exteriores da sua plataforma continental. Os limites da plataforma continental estabelecidas pelo Estado costeiro com base nessas recomendaçôes serão definitivos e obrigatórios".

Diante do estabelecido pelo parágrafo $8^{\circ}$, algumas questôes merecem ser elucidadas. Primeiramente, a seguinte: há obrigatoriedade de o Estado proponente aceitar as recomendações da CLPC para que sua decisão de estender sua plataforma continental seja válida no direito internacional e oponível aos demais membros da comunidade internacional? A resposta a esse questionamento é essencial para que se definam os limites do território marítimo brasileiro.

No intuito de colher os dados necessários para fundamentar a definição do limite exterior da sua plataforma continental, o governo brasileiro criou o Plano de Levantamento da Plataforma Continental Brasileira (LEPLAC), instituído pelo Decreto n. 98.145 , de 15 de setembro de 1989.

De acordo com informações da Comissão Interministerial para os Recursos do Mar (2010), as atividades do LEPLAC foram iniciadas em junho de 1987, com a primeira Comissão de Levantamento, efetuada pelo Navio Oceanográfico "Almirante Câmara", da Diretoria de Hidrografia e Navegação (DHN) da Marinha do Brasil.

Segundo a CIRM, com base em todo o material coletado, foi elaborada uma "Proposta de Limite Exterior da Plataforma Continental Brasileira", composta de três partes: Parte I - Sumário Executivo; Parte II - Corpo Principal; e Parte III Dados Científicos e Informações Técnicas de Apoio, a qual foi encaminhada à Comissão de Limites da Plataforma Continental (CLPC) da ONU em 17 de maio de 2004, por intermédio do Ministério das Relaçôes Exteriores, a fim de ser apreciada por esta Comissão (CIRM, 2010).

A apresentação e a defesa da proposta aconteceram no período de 30.08.2004 a 17.09.2004, perante a CLPC e uma subcomissão de sete peritos, designada para analisar detalhadamente a proposta.

Posteriormente, "interaçôes com essa subcomissão ocorreram em abril/maio de 2005, agosto/setembro de 2005, março e setembro de 2006. Em 27 de março de 2007 ocorreu a última interação com toda a CLPC, ocasião em que foram apresentados à Comissão, de modo mais aprofundado, os argumentos científicos e técnicos que serviram de base para a proposta brasileira" (CIRM, 2010).

Os 960 mil km² correspondentes à área total reivindicada além das 200 milhas náuticas se distribuem ao longo da costa brasileira, principalmente nas regiōes Norte (região do Cone do Amazonas e Cadeia Norte Brasileira), Sudeste (Região da Cadeia Vitória-Trindade e Platô de São Paulo) e Sul (região de Platô de Santa Catarina 
e Cone do Rio Grande), e equivalem à soma das áreas dos estados de São Paulo, Paraná, Santa Catarina e Rio Grande do Sul. Nesses termos, a área oceânica sob

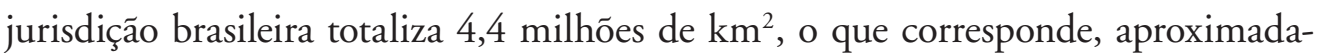
mente, à metade da área terrestre do território brasileiro ${ }^{6}$ (CIRM, 2010).

Em abril de 2007, após concluir a análise da proposta brasileira, a CLPC encaminhou suas recomendações ao governo brasileiro. Do total aproximado de 960 mil $\mathrm{km}^{2}$ de área reivindicada, além das 200 milhas náuticas, a CLPC não concordou com cerca de $190 \mathrm{mil} \mathrm{km}^{2}$, distribuídos nas seguintes áreas da plataforma continental brasileira: Cone do Amazonas, Cadeias Norte Brasileira e Vitória-Trindade e Margem Continental Sul. A área não aceita pela CLPC corresponde, aproximadamente, a 4,2\% da plataforma continental total e a 19\% da área da plataforma continental estendida (CIRM, 2010).

Como se depreende do exposto, as recomendações da CLPC não atenderam ao pleito brasileiro na sua totalidade, motivo pelo qual o Brasil não as aceitou.

De todo modo, cabe destacar que a CIRM, na sua $168^{a}$ Sessão Ordinária, decidiu que seja elaborada uma nova Proposta de Limite Exterior da Plataforma Continental Brasileira além das 200 milhas, a ser oportunamente encaminhada à CLPC.

Diante do exposto, discute-se a validade jurídica da decisão do governo brasileiro perante a comunidade internacional de não aceitar as recomendações formuladas pela CLPC, isto é, analisa-se a própria validade do território brasileiro tal qual estabelecido de forma unilateral.

Para se chegar a uma conclusão, analisa-se novamente o que diz o parágrafo $8^{\circ}$ do artigo 76 da Convenção de Montego Bay:

8. Informaçôes sobre os limites da plataforma continental, além das 200 milhas marítimas das linhas de base a partir das quais se mede a largura do mar territorial, devem ser submetidas pelo Estado costeiro à Comissão de Limites da Plataforma Continental, estabelecida de conformidade com o Anexo II, com base numa representação geográfica equitativa. A Comissão fará recomendações aos Estados costeiros sobre questôes relacionadas com o estabelecimento dos limites exteriores da sua plataforma continental. Os limites da plataforma continental estabelecidos pelo Estado costeiro com base nessas recomendações serão definitivos e obrigatórios (grifos nossos).

Note-se que a Convenção utiliza por duas vezes a expressão "recomendaçôes”, quando se refere ao pronunciamento exarado pela CLPC. Aldo Chircop e Bruce A. Marchand esclarecem a questão e afirmam que a CLPC não é um órgão

Devido à extensão do território pleiteado, e das riquezas naturais que ali se encontram, tem-se chamado essa área de Amazônia Azul. 
com funções determinativas, tendo competência apenas para analisar as submissões realizadas pelos Estados e propor recomendações, resguardando-se o direito de estabelecer os limites externos da plataforma continental aos Estados costeiros (2001, p. 29).

Ao tratar da natureza jurídica das recomendações na Organização Internacional do Trabalho, Mazzuoli sustenta que "ao contrário do que sucede com as demais recomendações conhecidas no Direito Internacional Público, que não criam obrigações jurídicas para os Estados que as adotam, as recomendações da OIT caracterizam-se por impor aos Estados-membros dessa organização internacional certas obrigações ainda que de caráter formal” (2010, p. 927).

Disto infere-se que, para o Direito Internacional Público, as recomendações, entre elas as formuladas pela CLPC, são um tipo de pronunciamento que revelam meros conselhos ou sugestões sobre uma questão de direito posta para análise. Assemelham-se, portanto, a um parecer, pelo qual o órgão competente emite uma opinião técnica em resposta a uma consulta.

Obrigatório, no entanto, é o ato de o Estado interessado em ampliar sua plataforma continental submeter as informações de que dispõe sobre as formações geológicas da sua costa a análise da Comissão de Limites da Plataforma Continental.

O fato de o parágrafo $8^{\circ}$ dispor que "os limites da plataforma continental estabelecidos pelo Estado costeiro com base nessas recomendações serão definitivos e obrigatórios" (grifos nossos) significa que quando a decisão tomada por um Estado, de ampliar sua plataforma continental, for embasada em uma recomendação da CLPC, tal decisão, além de válida perante a comunidade internacional, não poderá ser objeto de questionamentos posteriores.

Por outro lado, a decisão de um Estado não amparada por uma recomendação da CLPC, embora válida e oponível à comunidade internacional, poderá ser objeto de questionamento por outro Estado, que terá legitimidade para submeter um pedido de solução de controvérsia, em conformidade com os procedimentos expostos na Parte XV da Convenção. Nesse caso, a decisão proferida pelo órgão competente, esta sim, terá caráter definitivo e força obrigatória, conforme determina o parágrafo $1^{\circ}$ do artigo 296: "Qualquer decisão proferida por uma corte ou tribunal com jurisdição nos termos da presente seção será definitiva e deverá ser cumprida por todas as partes na controvérsia”.

Por fim, vale destacar que uma solução de controvérsia, instaurada perante um órgão competente para decidir a questão, poderá, inclusive, de acordo com o artigo 284 da Convenção, ser objeto de conciliação entre as partes envolvidas no litígio. Ou seja, mesmo diante da instauração de um pedido de solução de controvérsia 
contra os limites estabelecidos pelo Brasil, no que tange à extensão da sua plataforma continental, ainda seria possível se chegar a um acordo com o Estado reclamante, de modo que o objeto do acordo faria coisa julgada entre as partes, e os limites da plataforma continental brasileira, formulados unilateralmente, continuariam válidos até que outro interessado ingressasse com novo pedido de solução de controvérsia e a questão fosse posta novamente para apreciação.

Desse modo, atualmente a área total sobre a qual o Brasil exerce poderes de soberania, para fins de exploração e produção de petróleo, considerando as porções terrestres e marítimas do território, é de aproximadamente 13 milhões de metros quadrados. Dentro desse território, a Constituição Federal de 1988 estabeleceu que o petróleo existente no subsolo brasileiro, esteja ele presente no espaço terrestre ou no marítimo, é bem de propriedade da União. 
